\title{
AVALIAÇÃO DA CONTAMINAÇÃO DE EQUIPAMENTOS, UTENSÍLIOS E MÃOS DE MANIPULADORES DE UM SERVIÇO DE NUTRIÇÃO E DIETÉTICA
}

\author{
(Evaluation of contamination of equipment, utensils, and hands of food handlers of a \\ Hospital Nutrition and Dietetics Service)
}

\author{
Amanda de Oliveira dos Santos, Aryele Nunes da Cruz Encide Sampaio, Otávio Augusto \\ Martins, José Paes de Almeida Nogueira Pinto, Juliano Gonçalves Pereira* http://orcid.org/0000-0002- \\ $\underline{8713-7506}$ \\ Universidade Estadual Paulista "Júlio de Mesquita Filho" (UNESP) - Faculdade de Medicina \\ Veterinária e Zootecnia, Campus de Botucatu, Botucatu-SP. \\ *E-mail para contato: juliano.pereira@unesp.br
}

RESUMO - O Serviço de Nutrição e Dietética (SND) é o setor de um hospital responsável por desenvolver atividades relacionadas à alimentação e nutrição de pacientes, acompanhantes e colaboradores. O cuidado com a segurança dos alimentos no ambiente hospitalar é de importância fundamental, uma vez que os alimentos preparados neste local serão direcionados, na maioria das vezes, a pacientes imunocomprometidos. O objetivo do presente estudo foi avaliar as condições higiênico-sanitárias de superfícies de trabalho, equipamentos, utensílios e mãos de manipuladores de um SND de um hospital público do Centro-Oeste do Estado de São Paulo. Por meio de swab superficial, foram colhidas amostras de 101 superfícies, equipamentos e utensílios e de 46 mãos de manipuladores. As amostras foram submetidas às contagens de micro-organismos mesófilos, coliformes e Escherichia coli e nas mãos de manipuladores realizou-se também a contagem de Staphylococcus coagulase positiva. Foi observado que $51,4 \%$ das superfícies de trabalho, equipamentos, utensílios e superfícies apresentaram-se fora do padrão para mesófilos, $50,4 \%$ para coliformes e 3,9\% para $E$. coli. Das 46 mãos amostradas, 23,9\% apresentaram resultados fora do padrão para mesófilos, $32,6 \%$ para coliformes e apenas $2,1 \%$ para E. coli e Staphylococcus coagulase positiva. Os resultados demonstraram falhas no processo de higienização de superfícies, equipamentos, utensílios e mãos de manipuladores o que pode influenciar diretamente na qualidade e segurança dos alimentos oferecidos aos pacientes, acompanhantes e colaboradores.

Palavras-chave: micro-organismos; nutrição hospitalar; saúde.

ABSTRACT - The Nutrition and Dietetics Service (NDS) is the sector of a hospital responsible for developing activities related to food and nutrition for patients, companions and employees. Care for food safety in the hospital environment is of fundamental importance, since the food prepared in this location will be directed, in most cases, to immunocompromised patients. The objective of the present study was to evaluate the hygienic-sanitary conditions of surfaces, equipment, utensils and hands of food handlers of an NDS of a public hospital in the Midwest of the State of São Paulo. By means of a superficial swab, samples were collected from 101 surfaces, equipment and utensils and from 46 hands of food handlers. The samples were subjected to counts of mesophilic, coliform and Escherichia coli and the positive coagulase Staphylococcus count was also performed in the hands of food 
handlers. It was observed that $51.4 \%$ of the surfaces, equipment, utensils and surfaces were out of the standard for mesophiles, $50.4 \%$ for coliforms and $3.9 \%$ for E. coli. Of the 46 sampled hands, $23.9 \%$ showed non-standard results for mesophiles, $32.6 \%$ for coliforms and only $2.1 \%$ for E. coli and coagulase positive Staphylococcus. The results showed errors in the process of cleaning surfaces, equipment, utensils and hands, which can directly influence the quality and safety of the food offered to patients, companions and collaborators.

Keywords: health; hospital nutrition; microorganisms.

\section{INTRODUÇÃO}

O Serviço de Nutrição e Dietética (SND) é o setor hospitalar responsável pela alimentação e nutrição de pacientes, acompanhantes e trabalhadores, sendo o cuidado com a segurança dos alimentos de importância fundamental, uma vez que os alimentos preparados neste local serão direcionados para pacientes com imunidade debilitada e, portanto, mais susceptíveis a contrair Doenças Veiculadas por Alimentos (Saccol et al., 2013).

No Brasil, dentre os agentes etiológicos mais identificados nos surtos de DVA no período de 2009 a 2018, Escherichia coli foi o mais comum $(23,4 \%)$, seguida por Salmonella (11,3\%), Staphylococcus aureus $(9,4 \%)$ e bactérias do grupo coliformes (6,5\%) (Brasil, 2019). Em pacientes considerados grupo de risco como os hospitalizados, as DVA têm maior impacto, ressaltando a importância da adoção de práticas rigorosas de higiene na produção das refeições hospitalares (Gonçalves, 2012).

Os manipuladores de alimentos são considerados uma das principais vias de contaminação dos produtos e desempenham um papel importante na segurança e preservação da higiene dos alimentos durante toda a cadeia de produção (Bastos, 2008). Visando obter um alimento de qualidade e seguro, destaca-se como fundamental, os procedimentos operacionais padronizados de higienização de utensílios, equipamentos e do ambiente de produção, pois os alimentos estão susceptíveis à contaminações por micro-organismos associados à manipulação e aos procedimentos incorretos durante o processamento e distribuição (Bas et al. 2006). A higiene pessoal e a capacitação rotineira de manipuladores são essenciais para qualquer programa de prevenção em segurança dos alimentos (Silva Jr., 2007; Mello et al., 2010; Germano e Germano, 2011; Ribeiro, 2017).

Os manipuladores que apresentarem lesões ou sintomas de enfermidades que possam comprometer a qualidade higiênico-sanitária dos alimentos, devem ser afastados das atividades de preparo de alimentos enquanto persistirem essas condições de saúde (Brasil, 2004).

As Boas Práticas (BP), asseguram os parâmetros básicos de qualidade, assim como os procedimentos corretos de higiene e manipulação dos alimentos. A RDC 216 de 15 de setembro de 2004 dispõe sobre Regulamento Técnico de Boas Práticas para Serviços de Alimentação (Brasil, 2004). Entretanto, no que se refere às unidades de alimentação hospitalar, há uma carência de normas, o que obriga esses estabelecimentos a se adequarem a referida resolução para garantia da segurança dos alimentos (Gonçalves, 2012; Saccol et al., 2013).

A limpeza e sanitização de equipamentos são etapas importantes no controle sanitário (Andrade, 2008). Assim, avaliar constantemente as condições 
microbiológicas dos ambientes ligados ao pré-preparo e preparo dos alimentos é fundamental para evitar a sua contaminação (Silva Jr., 2007).

Para avaliar as condições ambientais nas quais os alimentos são preparados, deve-se analisar as superfícies de contato em todas as etapas de preparo, uma vez que os alimentos podem contaminar-se mediante contato com utensílios, superfícies e equipamentos mal higienizados (Silva Jr., 2007).

Como uma das formas de se avaliar o nível de contaminação de superfícies, devem ser realizadas análises microbiológicas rotineiras de equipamentos utilizados na produção. A obtenção de amostras através do swab superficial e a subsequente contagem de micro-organismos, permite detectar o grau de limpeza, assim como avaliar as condições de higiene das mãos dos manipuladores (Nogueira, 2016).

Baseado nessas informações, o objetivo do presente estudo foi avaliar as condições higiênico-sanitárias de superfícies, equipamentos, utensílios e mãos de manipuladores de um Serviço de Nutrição e Dietética de um hospital público do centro-oeste do estado de São Paulo.

\section{MATERIAL E MÉTODOS}

\section{Coleta de amostras}

O estudo foi realizado em uma cozinha de um SND de um hospital público situado no Centro-Oeste do Estado de São Paulo. As amostras foram coletadas durante o período de setembro de 2016 a maio de 2018. Foram obtidas 147 amostras oriundas de bancadas de trabalho $(n=30)$, superfície de corte de verdura $(n=13)$, utensílios gerais $(n=10)$, processador de alimentos $(n=9)$, mamadeira $(n=9)$, liquidificador $(n=8)$, fatiador de verduras e legumes $(n=6)$, fatiador de frios $(n=4)$, fatiador de carnes $(n=3)$, moedor de carne $(n=3)$, superfície de corte de carnes $(n=2)$, pia comum $(n=2)$, pia de carnes $(n=2)$ e mãos de manipuladores $(n=46)$.

Para a amostragem, utilizou-se swabs embebidos em $10 \mathrm{~mL}$ de solução salina $0,85 \%$. Após a imersão do swab na solução, foi amostrada uma área de 100 $\mathrm{cm}^{2}$ das superfícies com auxílio de um molde estéril de $10 \times 10 \mathrm{~cm}^{2}$. Para as mãos dos manipuladores, os swabs umedecidos foram aplicados no dorso e na face palmar de uma das mãos, e entre os dedos dos manipuladores sem a utilização de molde. Após coletadas, as amostras foram acondicionadas em caixas isotérmicas contendo gelo reciclável e transportadas ao laboratório para serem submetidas imediatamente às análises microbiológicas. Nas superfícies, equipamentos, utensílios e mãos foram realizadas as contagens de micro-organismos mesófilos, coliformes e E. coli, e além destas, nas mãos dos manipuladores, foi realizada a contagem de Staphylococcus coagulase positiva.

\section{Análises microbiológicas}

\section{Contagem de micro-organismos mesófilos}

Da amostra de swab acondicionado em solução salina $0,85 \%$ (diluição $10^{\circ}$ ), foram realizadas diluições decimais seriadas até a diluição $10^{-3}$. Posteriormente, 1 $m L$ de cada diluição foi semeada em placa de Petrifilm ${ }^{\mathrm{TM}} \mathrm{AC}$ (3M Company). Estas placas foram incubadas a $35^{\circ} \mathrm{C} \pm 1{ }^{\circ} \mathrm{C}$ por $48 \mathrm{~h} \pm 3 \mathrm{~h}$. Após o período de incubação, as placas foram interpretadas de acordo com as recomendações do fabricante e os 
resultados expressos em $U F C / \mathrm{cm}^{2}$ no caso das superfícies, equipamentos e utensílios e UFC/mão nas amostras obtidas de mãos de manipuladores.

\section{Contagem de coliformes e E. coli}

A partir das mesmas diluições decimais descritas acima descrita, $1 \mathrm{~mL}$ foi semeado em placas de Petrifilm ${ }^{\mathrm{TM}}$ EC (3M Company). Estas placas foram incubadas por $48 \mathrm{~h} \pm 2 \mathrm{~h}$ a $35{ }^{\circ} \mathrm{C} \pm 1{ }^{\circ} \mathrm{C}$. Após o período de incubação, as placas foram contadas de acordo com as recomendações do fabricante, sendo consideradas como E. coli as colônias azuis e com gás e como micro-organismos do grupo coliformes as colônias azuis com gás e bem como as vermelhas. O resultado foi expresso individualmente para cada micro-organismo (coliforme ou $E$. coli) e expresso em UFC/cm² no caso das superfícies, equipamentos e utensílios e UFC/mão nas amostras obtidas de mãos de manipuladores.

\section{Contagem de Staphylococcus coagulase positiva}

A partir das diluições acima, transferiu-se alíquotas de $0,1 \mathrm{~mL}$ para placas de Petri contendo Ágar Baird-Parker (BP, Difco), espalhando-se o inóculo até sua total absorção. Após a semeadura, as placas foram incubadas a $35^{\circ} \mathrm{C} \pm 1{ }^{\circ} \mathrm{C}$ por $48 \mathrm{~h} \pm$ 2 h. Após a incubação, foram contadas as colônias típicas e atípicas das placas com contagens entre 15 a 300. Colônias típicas apresentam-se circulares, negras ou cinza escura, lisas, convexas, com bordas perfeitas, rodeadas por uma zona opaca e halo transparente se estendendo além da zona opaca (Silva et al. 2017), sendo essas confirmadas por meio da realização do teste de coagulase. Selecionou-se prioritariamente cinco colônias típicas e na ausência parcial ou total de colônias típicas, selecionou-se as colônias atípicas, totalizando cinco colônias para o teste de coagulase. Cada colônia foi semeada em um tubo de ensaio contendo o caldo infusão cérebro-coração (BHI, Difco), sendo incubado a $35^{\circ} \mathrm{C} \pm 1^{\circ} \mathrm{C}$ por $24 \mathrm{~h} \pm 2 \mathrm{~h}$. Após este período, transferiu-se $0,1 \mathrm{~mL}$ de cada cultura do $\mathrm{BHI}$, para tubos estéreis contendo $0,3 \mathrm{~mL}$ de plasma de coelho (Laborclin) e incubou-os a $35{ }^{\circ} \mathrm{C} \pm 1{ }^{\circ} \mathrm{C}$, observando a formação de coágulo após 4-6 h. Quando negativo, completava-se a incubação para $24 \mathrm{~h}$. Considerou como coagulase positiva todos os tubos que apresentaram formação de coágulo ocupando mais da metade do volume original de líquido. Após a leitura, o resultado foi obtido de acordo com a proporção de colônias submetidas ao teste de coagulase que foram positivas, sendo os resultados expressos em UFC/mão de manipulador.

\section{RESULTADOS E DISCUSSÃO}

$\mathrm{Na}$ literatura existem padrões de referências internacionais para classificação das condições higiênico-sanitária dos ambientes ligados ao preparo dos alimentos, tais como as recomendações da American Public Health Association - APHA (Petran et al., 2015) e da Organização Panamericana de Saúde (OPAS, 2006). Porém, tais recomendações muitas vezes não podem ser aplicadas ao Brasil, pois são consideradas muito rígidas para as unidades de alimentação e nutrição brasileiras (Andrade, 2008).

Nesse estudo, foram utilizados como valores de referência, os descritos por Silva Jr. (2007). Seguindo estas recomendações, o presente estudo aceitou como resultado satisfatório contagens de até $50 \mathrm{UFC} / \mathrm{cm}^{2}$ de micro-organismos mesófilos 
e ausência de coliformes termotolerantes, representados neste estudo pela $E$. coli para superfícies, equipamentos e utensílios. Deste modo, seguindo o padrão apresentado por Silva Jr. (2007), a Tabela 1 apresenta o número de amostras fora do padrão, ou seja, as que apresentam resultado superior a $50 \mathrm{UFC} / \mathrm{cm}^{2}$ para mesófilos ou a presença de micro-organismos do grupo coliformes ou $E$. coli.

Observou-se que 52 (51,4\%) amostras de superfícies, equipamentos e utensílios apresentaram contagens acima de $50 \mathrm{UFC} / \mathrm{cm}^{2}$ de mesófilos, demonstrando condições higiênicas insatisfatórias, representando riscos à saúde dos consumidores e/ou pacientes.

Em relação aos coliformes, dos 13 tipos de amostras analisados, 12 obtiveram presença de coliformes em ao menos uma amostra, totalizando 51 (50,4\%). Para E. coli, amostras positivas foram observadas em superfícies de corte de verduras, superfície de corte de carne e moedor de carne, totalizando quatro amostras (3,9\%).

Tabela 1 - Número de amostras consideradas fora do padrão para mesófilos, coliformes e Escherichia coli em amostras de superfícies, utensílios e equipamentos de um Serviço de Nutrição de um hospital público do Centro-Oeste do Estado de São Paulo.

\begin{tabular}{|c|c|c|c|}
\hline \multirow{2}{*}{ Amostras } & \multicolumn{3}{|c|}{$\mathbf{N}(\%)$ de amostras fora do padrão ${ }^{1}$} \\
\hline & Mesófilos & Coliformes & E. coli \\
\hline Bancada $(\mathrm{n}=30)$ & $5(16,6)$ & $9(30)$ & $0(0)$ \\
\hline $\begin{array}{l}\text { Superfície de corte de verdura } \\
(n=13)\end{array}$ & $9(69,2)$ & $10(76,9)$ & $1(7,6)$ \\
\hline Utensílios gerais ${ }^{2}(\mathrm{n}=10)$ & $6(60)$ & $5(50)$ & $0(0)$ \\
\hline Processador de alimentos $(n=9)$ & $9(100)$ & $7(77,7)$ & $0(0)$ \\
\hline Mamadeira $(n=9)$ & $0(0)$ & $0(0)$ & $0(0)$ \\
\hline Liquidificador $(\mathrm{n}=8)$ & $6(75)$ & $2(25)$ & $0(0)$ \\
\hline $\begin{array}{l}\text { Fatiador de verduras e legumes } \\
(n=6)\end{array}$ & $6(100)$ & $5(83,3)$ & $0(0)$ \\
\hline Fatiador de frios $(n=4)$ & $1(25)$ & $3(75)$ & $0(0)$ \\
\hline Fatiador de carnes $(n=3)$ & $2(66,6)$ & $3(100)$ & $0(0)$ \\
\hline Moedor de carne $(n=3)$ & $3(100)$ & $3(100)$ & $2(66,6)$ \\
\hline $\begin{array}{l}\text { Superfície de corte de carnes } \\
(n=2)\end{array}$ & $2(100)$ & $2(100)$ & $1(50)$ \\
\hline Pia comum $(n=2)$ & $1(50)$ & $1(50)$ & $0(0)$ \\
\hline Pia de carnes $(n=2)$ & $2(100)$ & $1(50)$ & $0(0)$ \\
\hline Total $(n=101)$ & $52(51,4)$ & $51(50,4)$ & $4(3,9)$ \\
\hline
\end{tabular}

Os coliformes são micro-organismos distribuídos amplamente na natureza. Dentro deste grupo, a espécie mais importante é a $E$. coli, uma vez que seu habitat primário é o trato intestinal sendo, portanto, eliminada pelas fezes de humanos e animais (Franco e Landgraf, 2003). Uma vez que alimentos são contaminados por fezes, não somente $E$. coli pode ser encontrada nos produtos, mas também outros 
patógenos, como Salmonella, que também tem como principal via de contaminação de alimentos a fecal.

Segundo Silva et al. (2017), o grupo dos coliformes indica as condições de higiene dos processos de fabricação, por ser um grupo de micro-organimos facilmente inativados pelos sanitizantes e capazes de estarem presentes em várias etapas do processamento, quando a sanitização é falha. Apesar dos equipamentos e utensílios de cozinha serem construídos de materiais de fácil higienização como aço inoxidável e plástico, alguns dos equipamentos avaliados nesse estudo, apresentavam layout de acabamento complexo, ou seja, apresentam reentrâncias, número elevado de peças e dificuldade de desmontagem que não permitia uma higiene adequada após o seu uso, o que pode ser uma justificativa, portanto, para o número de amostras fora do padrão, principalmente para mesófilos e coliformes.

Ao avaliar as condições higiênicas de Unidades de Alimentação e Nutrição dos Hospitais Universitários do Rio Grande do Norte, Barbosa et al. (2018) encontraram, um percentual superior a $50 \%$ de amostras fora dos padrões aceitáveis para mesófilos e coliformes termotolerantes. Tais autores descrevem que tais resultados são preocupantes, visto que falhas no processo de higienização de equipamentos e utensílios, podem contribuir para a disseminação de microorganismos patogênicos no ambiente de preparo e, portanto, representam risco de ocorrência de surtos de DVA. A presença de coliformes nas superfícies de manipulação de alimentos, como indicadores de contaminação de alimentos, reflete falhas na conduta higiênica dos colaboradores, especialmente, no que se refere ao processo de higienização das mãos (Barbosa et al., 2018).

Coelho et al. (2010) ao avaliar a presença de micro-organismos mesófilos nas superfícies de bancadas, utensílios e equipamentos em restaurantes comerciais, no município de Viçosa, Minas Gerais, verificaram que $84,6 \%$ das amostras demonstraram inadequação $\left(>50 \mathrm{UFC} / \mathrm{cm}^{2}\right)$ quanto à segurança dessas superfícies no aspecto higiênico-sanitário, podendo comprometer a qualidade microbiológica dos alimentos que entram em contato direto com os mesmos.

Stangarlin (2014) ao comparar as condições higiênico-sanitárias de superfícies em contato com os alimentos, antes e após adequação dos requisitos de higiene e capacitação dos manipuladores de alimentos em um SND hospitalar, observou que após a adequação e capacitação, houve uma diminuição na contagem de micro-organismos mesófilos em $80 \%$ das superfícies analisadas. O resultado reforça a importância da adequação dos requisitos de higiene e capacitação, para a segurança dos alimentos que são manipulados nesses locais.

De acordo com a RDC 216 (Brasil, 2004) as instalações, equipamentos, móveis e utensílios devem ser mantidos em condições higiênico-sanitárias apropriadas. As operações de higienização devem ser realizadas por funcionários capacitados e com frequência que garanta a manutenção dessas condições e minimize o risco de contaminação do alimento. A área de preparação do alimento deve ser higienizada quantas vezes forem necessárias e imediatamente após 0 término do trabalho.

Da mesma forma que não existem parâmetros legais para superfícies, utensílios e equipamentos, não há uma legislação brasileira que estabeleça parâmetros microbiológicos para mão de manipuladores de alimentos. Andrade (2008) determinou faixas de contagens que pudessem servir de orientação para definir as condições higiênicas de mãos de manipuladores no Brasil, sendo, para mesófilos aeróbios até $10^{3} \mathrm{UFC} /$ mão (faixa I) e entre $10^{3}$ e $10^{4} \mathrm{UFC} /$ mão (faixa II). Considerando a necessidade de adoção de práticas rigorosas de segurança de 
alimentos na produção das refeições hospitalares, o presente estudo utilizou como parâmetro a Faixa I.

Para micro-organismos do grupo dos coliformes e E. coli em mãos de manipuladores, Silva Jr. (2007) e Tondo e Bartz (2013) consideram a ausência como resultado satisfatório. Para Staphylococcus coagulase positiva, Silva Jr. (2007) considera aceitável a contagem de até $10^{2}$ UFC, sendo esse utilizado como referência no presente estudo.

Das 46 amostras de mão de manipuladores analisadas, 11 (23,9\%) apresentaram resultados fora do padrão para mesófilos. A maioria das mãos apresentou contagens de mesófilos relativamente baixas, demostrando uma higienização satisfatória, porém algumas mãos apresentaram contagens elevadas, o que revela falhas durante o processo de higienização sendo, dessa forma, necessário uma atenção especial para identificar falhas e assim corrigi-las.

Em um estudo comparativo das condições higiênicas das mãos de colaboradores de um restaurante em Brasília, antes e após a higienização, Nascimento e Queiroz (2017) constataram condições sanitárias insatisfatórias das mãos dos colaboradores em todas as etapas, quando comparadas ao padrão de contagem proposto por Andrade (2008).

Stangarlin (2014) ao comparar a contagem de mesófilos nas mãos de manipuladores de alimentos em SND Hospitalar, antes e após adequação dos requisitos de higiene e capacitação, constatou que após esse processo, houve uma diminuição média de 2,07 log UFC/mão. Seu resultado evidenciou a importância da correta higiene das mãos e capacitação dos manipuladores, pois melhorou 0 conhecimento dos manipuladores e comprovou a eficiência dos procedimentos de higienização.

Outros micro-organismos detectados neste estudo foram os coliformes em $32,6 \%$ das mãos e E. coli e Staphylococcus coagulase positiva, que estavam presentes em apenas uma mão $(2,1 \%)$ o que aponta um risco pela capacidade de Staphylococcus coagulase positiva, sobretudo $S$. aureus, de produzir toxinas que levam à intoxicação alimentar.

Dentre os micro-organismos patogênicos importantes para a ocorrência de DVA, os mais pesquisados em análise de mãos, são Staphylococcus aureus e micro-organismos do grupo coliformes, dentre eles E. coli. A E. coli tem como habitat natural o trato intestinal de animais de sangue quente, embora possa ser introduzida nos alimentos por meio de fontes não fecais. Sua presença demonstra apenas a probabilidade de presença de contaminação fecal (Silva et al., 2017). Ao pesquisar coliformes totais e termotolerantes nas mãos de manipuladores de alimentos de um SND hospitalar no Rio Grande do Sul, Schumann et al. (2016) constataram que de 25 manipuladores avaliados, apenas 4 (16\%) apresentaram resultados insatisfatórios para coliformes totais e $2(8 \%)$ para coliformes termotolerantes.

No estudo de Stangarlin (2014), ao analisar as mãos dos manipuladores, constatou-se inicialmente que $94 \%$ para coliformes totais e $97 \%$ para coliformes termotolerantes encontravam-se dentro dos limites aceitáveis e, após adequação dos requisitos de higiene e capacitação, todas as amostras demonstraram ausência dos referidos micro-organismos.

O grupo dos Staphylococcus coagulase positiva compreende $S$. aureus, $S$. intermedius, S. delphini e S. schleiferi subsp. coagulans. Essas espécies são consideradas,patogênicos ao humano sendo a produção de coagulase considerada 
uma indicação de patogenicidade entre as espécies de Staphylococcus (Silva et al., 2017).

O reservatório de $S$. aureus são os seres humanos e animais de sangue quente, ocorrendo nas fossas nasais, garganta, pele e cabelos de $50 \%$ ou mais indivíduos humanos saudáveis. A presença de números elevados de $S$. aureus é uma indicação de perigo potencial à saúde pública devido à produção da enterotoxina estafilococócica, bem como é um indicativo de higienização inadequada, principalmente quando o processamento envolve manipulação de alimentos, visto que os manipuladores são a fonte mais frequente de contaminação, embora os equipamentos e superfícies do ambiente também são capazes de contaminar os alimentos (Franco e Landgraf, 2003; Silva et al., 2017).

Ao pesquisar $S$. aureus nas mãos e mucosas nasais de 90 manipuladores de alimentos em unidades de alimentação e nutrição de Curitiba, Bresolin et al. (2005), constataram a sua presença em 31 mãos, confirmando assim uma má higienização das mesmas. Os autores observaram ainda que, nos manipuladores de alimentos das unidades de alimentação e nutrição hospitalares, os procedimentos de lavagem nas mãos não eram padronizados, pois alguns manipuladores usavam apenas água, outros água e sabão e poucos fizeram uso de um antisséptico pós-lavagem.

Em contrapartida, no estudo de Stangarlin (2014), tanto antes quanto após as adequações dos requisitos de higiene e capacitação, todas as avaliações de Staphylococcus coagulase positiva foram consideradas satisfatórias, demonstrando ausência do micro-organismo.

A RDC 216 preconiza que os manipuladores devem lavar cuidadosamente as mãos ao chegar ao trabalho, antes e após manipular alimentos, após qualquer interrupção do serviço, após tocar materiais contaminados, após usar os sanitários e sempre que se fizer necessário (Brasil, 2004).

Segundo Stangarlin (2014), a manutenção dos procedimentos corretos de higienização nas etapas de preparação dos alimentos é uma condição que deve ser considerada no tratamento e recuperação dos pacientes hospitalizados, pois está diretamente relacionada com o desenvolvimento de complicações e tempo de internação. Ressaltando ainda, que as capacitações auxiliam e devem ser realizadas frequentemente para que os comportamentos adquiridos se tornem um hábito.

Ribeiro (2017) complementa que, a lavagem das mãos é uma medida eficaz de prevenção da transmissão cruzada de micro-organismos e, apesar da relativa simplicidade deste procedimento, ainda se observa uma forte resistência à sua utilização. A higienização adequada dos equipamentos e utensílios bem como a do próprio manipulador é um dos fatores mais importante para o controle de qualidade do alimento (Saccol, et al., 2006).

A realização de capacitações periódicas para os manipuladores de alimentos, pode diminuir as falhas encontradas, de modo a contribuir para a melhoria das práticas referentes à manipulação segura dos alimentos, melhoria das condições higiênico-sanitárias do ambiente de produção e consequentemente o fornecimento de refeições seguras (Barbosa et al., 2018).

\section{CONCLUSÃO}

Conclui-se que o SND avaliado apresentou falhas no processo de higienização de superfícies, equipamentos e utensílios e falhas no processo de higiene pessoal de manipuladores do setor uma vez que mais da metade das amostras ambientais e das mãos apresentaram resultados insatisfatórios para ao menos um dos grupos de micro-organismos avaliados. 
Indica-se que os manipuladores deste local devam ser treinados e conscientizados quanto à importância da utilização das técnicas adequadas de higienização tanto das suas mãos quanto dos utensílios, equipamentos e superfícies de modo a garantir a produção e distribuição de alimentos seguros aos pacientes, acompanhantes e colaboradores.

\section{REFERÊNCIAS}

ANDRADE, N. J. Higiene na indústria de alimentos: avaliação e controle da adesão e formação de biofilmes bacterianos. São Paulo: Editora Varela, 2008.

BARBOSA, F. M. Faça o que eu digo ou faça o que eu faço? Avaliação das Boas Práticas de Manipulação em Unidades de Alimentação e Nutrição. 2018. 65 f. Dissertação (Mestrado em Nutrição) - Universidade Federal do Rio Grande do Norte, Natal, 2018.

BAS, M.; ERSUN, A.S.; KIVANC, G. The evaluation of food hygiene knowledge, attitudes, and practices of food handlers in food businesses in Turkey. Food Control, v.17, p.22, 2006.

BASTOS, C. C. B. Condições higiênico-sanitárias no preparo de refeições em creches comunitárias de Belo Horizonte, Minas Gerais. 2018. 112 f. Dissertação (Mestrado) - Universidade Federal de Minas Gerais, Belo Horizonte, 2008.

BRASIL. Ministério da Saúde. Resolução RDC 216, de 15 de setembro de 2004. Aprova o regulamento técnico de boas práticas para serviços de alimentação. Diário Oficial da União, Brasília, 2004.

BRASIL. Ministério da Saúde. Secretaria de Vigilância em Saúde. Surtos de Doenças Transmitidas por Alimentos no Brasil - Informe 2018, 2019. Disponível em: <https://portalarquivos2.saude.gov.br/images/pdf/2019/fevereiro/15/Apresenta---o-Surtos-DTA---Fevereiro-2019.pdf>, Acesso em 20 de abril de 2020.

BRESOLIN, B.M.Z.; DALL'STELLA, J.K.; FONTOURA-DA-SILVA, S.E. Pesquisa sobre a bactéria Staphylococcus aureus na mucosa nasal e mãos de manipuladores de alimentos em Curitiba/Paraná/Brasil. Revista Estudos de Biologia, v.27, n.59, p. 27-32, abr./jun. 2005.

COELHO, A.I.M.; MILAGRES, R.C.R.M.; MARTINS, J.F.L. et al. Contaminação microbiológica de ambientes e de superfícies em restaurantes comerciais. Ciência \& Saúde Coletiva, v.15 (Supl. 1), p.1597-1606, 2010.

FRANCO, B.D.G.M.; LANDGRAF, M. Microbiologia dos alimentos. São Paulo: Atheneu, 2003.

GERMANO, P.M.L.; GERMANO, M.I.S. Higiene e vigilância sanitária dos alimentos: qualidade das matérias-primas, doenças transmitidas por alimentos, treinamentos de recursos humanos. 4. ed. Barueri: Editora Manole, 2011. 
GONÇALVES, J.M. Avaliação das Boas Práticas adotadas nas cozinhas hospitalares da cidade de Pelotas/RS. 2012. 61f. Dissertação (Mestrado em Ciências da Saúde) - Universidade Federal de Pelotas, Pelotas, 2012.

MELLO, A.G.; GAMA, M.P.; MARIN, V.A. et al. Conhecimento dos manipuladores de alimentos sobre boas práticas nos restaurantes públicos populares do Estado do Rio de Janeiro. Brazilian Journal of Food Technology, Campinas, v.13, n.1, p. 60-68, 2010.

NASCIMENTO, F.C.; QUEIROZ, V.V. Qualidade microbiológica das mãos de manipuladores de alimento em um restaurante de Brasília-DF. Revista Científica Sena Aires. 2017; v.6, n.2, p. 109-15,2017.

NOGUEIRA, J.P. Análise microbiológica de superfícies de manipulação de alimentos em cantinas de uma universidade pública. 2016. 15f. Monografia (Nutrição) - Universidade Federal do Rio Grande do Norte, Natal, 2016.

OPAS - ORGANIZAÇÃO PAN-AMERICANA DA SAÚDE. Organização Mundial da Saúde (OMS). Codex alimentarius, Higiene dos Alimentos - Textos Básicos. Brasília: Agência Nacional de Vigilância Sanitária, OPAS, 2006.

PETRAN, R.L., GRIEME, L.E., FOONG-CUNNINGHAM, S., 2015. Culture methodes for enumeration of microrganisms. In: SALFINGER, Y. \& TORTORELLO, M. L. (eds.), Compendium of Methods for the Microbiological Examination of Foods, $5^{\text {th }}$ ed. Washington: American Public Health Association (APHA), 2015.

RIBEIRO, E.S.S. Condições higiênico-sanitárias de uma unidade de alimentação e nutrição hospitalar: manipuladores de alimentos em foco. 2017. 69 f. Monografia (Nutrição) - Universidade Federal do Rio Grande do Norte, Natal, 2017.

SACCOL, A.L.F.; HECKTHEUER, L.H.; RICHARDS, N.S. et al. Lista de Avaliação de Boas Práticas para Serviços de Alimentação - Resolução - RDC 216/2004 ANVISA. São Paulo: Varela; 2006.

SCHUMANN, A.C.; GHISLENI C.P.; SPINELLI, R.B. et al. Avaliação microbiológica de mãos dos manipuladores de alimentos e de utensílios de cozinha do serviço de nutrição de um hospital do norte do estado do rio grande do sul. Revista Perspectiva, Erechim. v. 41, n.153, p. 07-17, 2017.

SILVA, N.; JUNQUEIRA, V.C.A. SILVEIRA, N.F.A. et al. Manual de métodos de análise microbiológica de alimentos e água. 5. ed. São Paulo: Blucher, 2017.

SILVA JR., E.A. Manual de Controle Higiênico-sanitário em Serviços de Alimentação. 7. ed. São Paulo : Livraria Varela, 2007.

STANGARLIN, L. Ferramenta para implementação dos requisitos higiênicosanitários em serviços de nutrição e dietética hospitalar. 2014. Tese (Doutorado em Ciência e Tecnologia dos Alimentos) - Universidade Federal de Santa Maria, Santa Maria, 2014. 
SACCOL, A.L.F.; SERAFIM, A.L.; STANGARLIN, L. et al. Instrumentos de apoio para implantação das boas práticas em serviços de nutrição e dietética hospitalar. Rio de Janeiro: Rubio, 2013.

TONDO, E.C.; BARTZ, S. Microbiologia e Sistemas de Gestão da Segurança de Alimentos. Porto Alegre: Editora Sulina, 2013. 